\title{
Prostate Cancer Diagnostic and Evaluation in Gaza-Strip, Palestine
}

\author{
Y. S. M. Alajerami1 ${ }^{*}$, K. M. Abushab1, S. I. Alagha1, A. M. Beeram², Ahmed Najim1, Roentgen1 \\ ${ }^{1}$ Department of Medical Radiology, Al-Azhar University, Gaza Strip, Palestine \\ ${ }^{2}$ Department of Computed Tomography, Al-Shifa Hospital, Gaza Strip, Palestine \\ Email: "Yasser_ajr@hotmail.com
}

Received 31 August 2015; accepted 15 November 2015; published 18 November 2015

Copyright (C) 2015 by authors and Scientific Research Publishing Inc.

This work is licensed under the Creative Commons Attribution International License (CC BY).

http://creativecommons.org/licenses/by/4.0/

(c) (i) Open Access

\section{Abstract}

Prostate cancer has the third highest cancer incidence in Palestinian men with incidence rate about 4.5/100,000, and an increase in new cases by $50 \%$ between 2000 and 2015. Prostate cancer death rates have been obviously decreased in many countries due to treatment, precise screening. The current study aims to review and evaluate the new diagnosed prostate cancer in the Gaza Strip, Palestine. As a cross-sectional, quantitative and analytical approach based on structured review, the current study was conducted at Al-Shifa and European hospitals (main oncology departments in governmental hospitals). Interviews with newly diagnosed cancer prostate patients were carried out during the period of March and June, 2014; a total of 41 newly diagnosed with primary cancer prostate. Furthermore, demographic, health status, medical investigations and tests are reported from oncologists and hospital archives over the last five years $(2010-2014)$. The current study showed that there were 41 new prostate cancer cases in three months with incidence rate 5.1 per 100,000 . The highest rate of incidence was among the patients above age of $70+$, $70-74(29.3 \%)$. The results showed that $58.1 \%$ of the patients were smokers, and $22.6 \%$ used to smoke, while $16.1 \%$ responded they don't smoke at all. The most common type of treatment used by participants was chemotherapy therapy followed by hormonal therapy and prostatectomy. The least common methods used for treatment were radiation therapy and combination of hormonal, radiation, and chemotherapy as only 5 participants used each type of these treatment options. The prevalence of prostate cancer was higher among men who lived in Gaza Governorate compared to other governorates. Limited use of radiation therapy was due to the unavailability of this treatment in Gaza Strip.

\section{Keywords}

Prostate Cancer, Diagnostic and Evaluation, Gaza Strip

\footnotetext{
${ }^{*}$ Corresponding author.
}

How to cite this paper: Alajerami, Y.S.M., Abushab, K.M., Alagha, S.I., Beeram, A.M., Najim, A. and Roentgen (2015) Prostate Cancer Diagnostic and Evaluation in Gaza-Strip, Palestine. Health, 7, 1552-1559. 


\section{Introduction}

Prostate is located just below the bladder and surrounds the urethra [1]. Prostate is an exocrine gland of the male reproductive system, which secretes milky alkaline fluid, and it constitutes $30 \%$ of the semen [2]. In addition, the muscles of the prostate gland also help propel the semen into the urethra during ejaculation. However, sometimes there becomes a flaw of the prostate gland; a damage of normal tissues DNA occurs. If the growth of these damaged tissues of prostate becomes out of control, it might produce cancer. Cancer cells continue to grow and form new abnormal cells and it can invade other tissues and harm the body by forming lumps or masses of tissue called metastatic deposits.

Prostate cancer is a common health problem among men. Most prostate cancers grow slowly, and don't cause any health problems in men who have them. The majority of cases start to develop at the age of 50 years, and reaching its peak at 60 - 70 years of age. Prostate cancer is the second most frequently diagnosed cancer among men worldwide, and the sixth leading cause of cancer death among men. The symptoms of this cancer are not recognized with all patients and might not have any at all during the disease. Therefore, it needs good methods of diagnosis. There are no specific tests available with high accuracy to screen men for early detection of prostate cancer. The incidence of prostate cancer increases by some factors like age, family history, meat diet, some hormones, occupational and exposure history [3]-[5]. Close relation between prostate cancer complains and urinary symptoms exists. Urinary symptoms are nonspecific and include multi-complains i.e., frequent urination, dysuria, hematuria and a weak stream. More widespread disease often spreads to the bones and gives pain or unexplained weight loss and fatigue. Diagnosis is made using a digital rectal examination to feel the prostate and a blood test for PSA. A rectal ultrasound can image the prostate and multiple needle biopsies are used to detect the disease and determine its aggressiveness (the Gleason grade of 1 - 5 is added from two samples to form a score; low scores of 2 - 4 indicate slow growing disease).

One of the most side effects of prostate cancer is erectile dysfunction (inadequate erection). This complication may be related directly to the prostate tissue alteration and also can be attributed to the long-term therapy (surgical, chemical, hormonal and radiation therapy) [6]-[9]. Furthermore, several studies have found that posttreatment erectile dysfunction may not be associated with declines in overall quality of life [10]-[12]. Other studies revealed that the sexual dysfunction is highly related to psychosocial status of patients, which affects negatively on their potency.

In the Gaza Strip, prostate cancer is the third most common cancer with an incidence rate of $\sim 4.5 / 100,000$ and prevalence rate of $\sim 40 / 100,000$. These figures show an increasing of about 50\% between 2000 and 2014 [13].

We are full of hope to recommend the best solutions that may reduce the incidence of prostate cancer in the Gaza Strip. The aim of this study is to evaluate the cases, which diagnosed with prostate cancer in Gaza Strip during 2014.

\section{Methodology}

\subsection{Study Design and Setting Process}

A cross-sectional descriptive design with quantitative and qualitative approaches was applied in this study. This design will help in describing the study variables at a certain, fixed point of time. The data collection was performed at the Hemato-Oncology Clinic of the two main hospitals in Gaza Strip (Al-Shifa and European Gaza Hospital). In such an interview, a set of prepared questions acts as a guide for the researcher. While the researcher will work to ensure that certain key questions are asked of every person interviewed, the semi-structured format also allows and encourages the researcher to interject with additional questions as appropriate.

The study population of the current research consisted of all the patients that have been diagnosed with prostate cancer in Gaza Strip during 2014. All the clinical files of prostate cancer were collected from the oncology departments of Al-Shifa and European hospitals followed by face to face interview.

To facilitate the coding, sorting, and management of qualitative data, a set of analytic codes was developed to account for these topics and domains by using different tests and data sets proportion.

\subsection{Description of the Sample}

The target population for this study was all participants who were diagnosed with prostate cancer during the year 2014 and still living in the Gaza Strip. The sample frame included prostate cancer patients who were receiving 
treatment and patients who had already finished their treatment at the time of data collection between January and March 2015.

All clinical and medical files of prostate cancer were collected from the oncology departments of Al-Shifa and European hospitals. The patients who have died were excluded from the current study. All ethical considerations (Ministry of Health approval and signed consent form) were performed to conduct the research.

The collected data were tabulated, then through the use of SPSS program (software package used for statistical analysis), version-16 that facilitates the coding, sorting, and management of qualitative data, a set of analytic codes to account, explore and analyze by using different tests.

\section{Results}

The current study recorded 41 patients diagnosed with cancer prostate at the departments authorized to report and record theses cases (Al-Shifa and Gaza-European hospitals).

The current investigation revealed that the incidence rate of cancer prostate in Gaza strip was 5.1 per 100,000. The highest incidence of prostate cancer was among patients at 70 years or older (29.3\%).

\subsection{Diet, Obesity and Cigarette Smoking Habits}

The current results showed that $77.4 \%$ of the recorded patients suffered obesity and $61.3 \%$ of the patients are vegetarians. Regarding smoking habits, more than $58.1 \%$ of the patients are smokers, and $22.6 \%$ used to smoke. Figure 1 graphs the relationship between diet, obesity and cigarette smoking with prostate cancer.

\subsection{Prostatitis, Diabetes and Family History}

Figure 2 revealed that $58 \%$ of the recorded patients don't suffer from prostatitis, $90.3 \%$ of the patients don't have diabetes, and $77.4 \%$ of the current cases don't have family history with prostate cancer.

\subsection{Symptoms Related to Prostate Cancer}

Table 1 illustrates the complains and symptoms that reported with the new diagnosed patients. Obviously, the main warning sign was dysuria (75\%), urinary frequency especially at night (71\%). Furthermore, $54.8 \%$ of the recoded symptoms were hematuria and urgency, $45.2 \%$ impotence, and $19.4 \%$ haematospermia.

\subsection{Gleason Score}

Figure 3 shows the evaluation of prostate cancer prognosis based on Gleason Grading system. Obviously, the majority of the recorded cases are grade $3+5$ (39\%), while 7.3\% are grade Gleason $3+4$ [14]-[16].

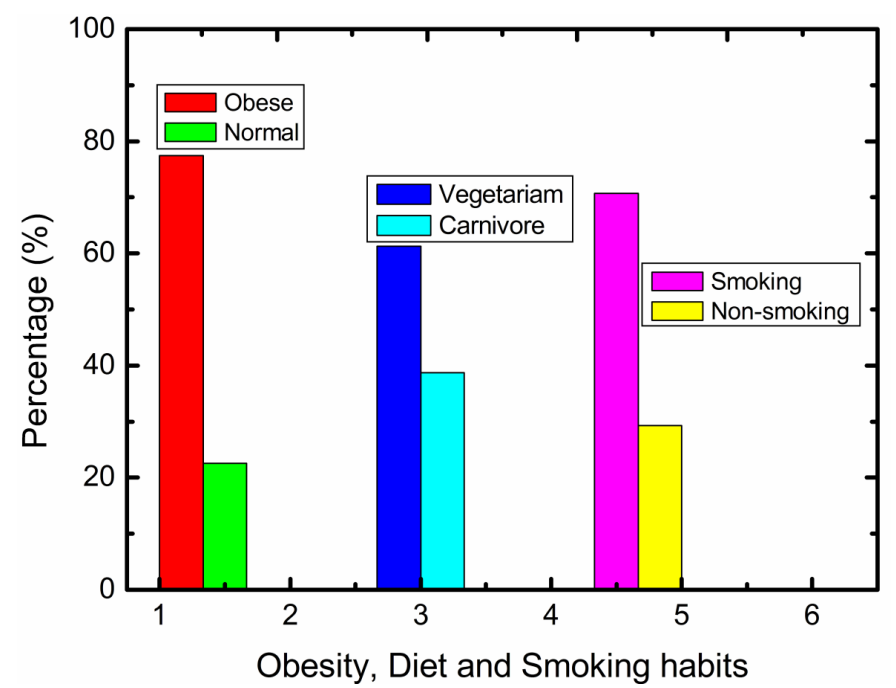

Figure 1. The relationship between diet/obesity/cigarette smoking and prostate cancer. 


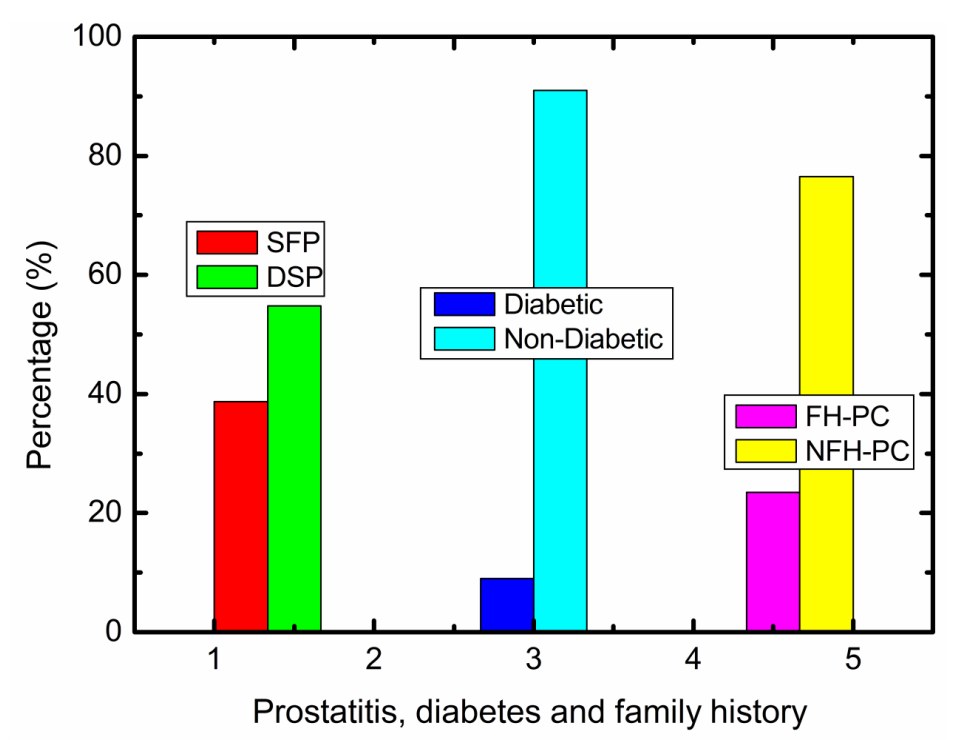

Figure 2. The relationship between prostatitis/diabetes/family history and prostate cancer (SFP: suffered from prostatitis, DSP: don’t suffer prostatitis, FH-PC: family history with prostate cancer, NFH-PC: no family history with prostate cancer).

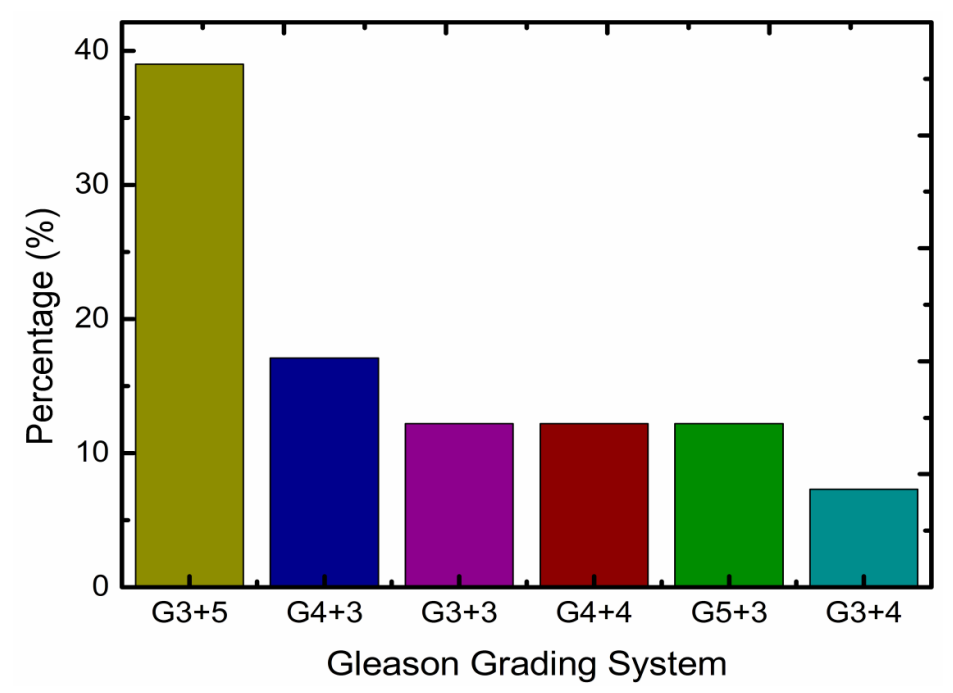

Figure 3. Prostate cancer prognosis based on Gleason's score.

Table 1. Incidence of symptoms related to prostate cancer patients.

\begin{tabular}{cccccc}
\hline Symptoms & Dysuria & Urinary frequency & Sudden need to urinate & Impotence & Blood in semen \\
\hline Percent \% & 75 & 71 & 54.8 & 45.2 & 19.4 \\
\hline
\end{tabular}

\subsection{Diagnosis and Treatment}

The sensitivity of the Prostate-specific antigen (PSA) was 90.2\%, while for Ultrasound (Transabdominal and Transrectal) was 36.3\%, and for digital rectal exam (DRE) was only 26.8\% as shown in Figure 4.

The most common type of treatment used by participants was Chemotherapy $(70.7 \%)$ followed by Hormonal therapy (primary or secondary treatment) $(41.5 \%)$ and then prostatectomy with $22 \%$. The least common methods used for treatment were radiation therapy and combination of hormonal, radiation, and chemotherapy as only $12.2 \%$ used each type of these treatment options. 


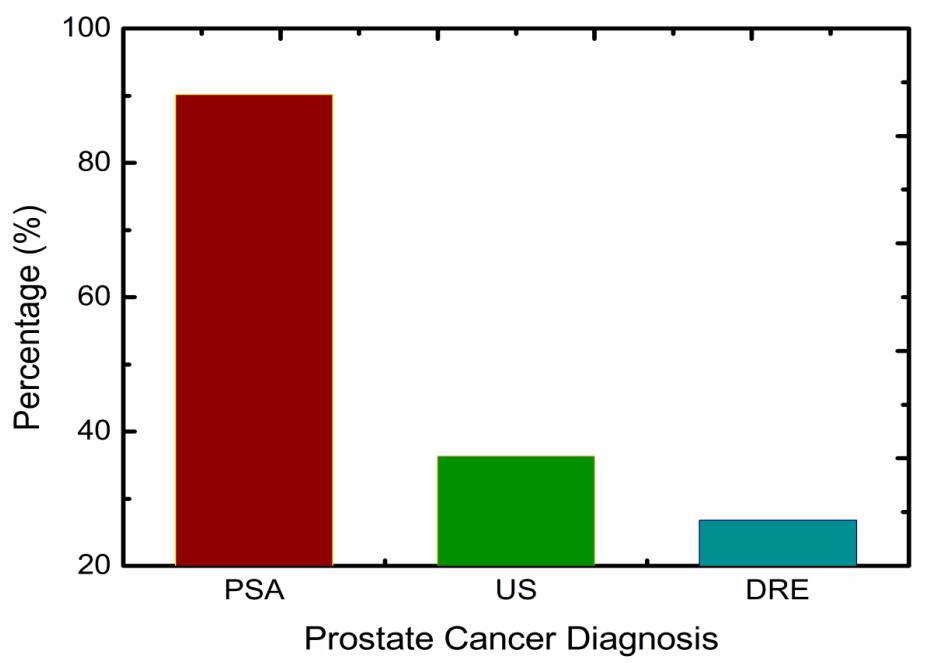

Figure 4. Prostate cancer diagnosis [PSA: prostate-specific antigen; US: ultrasound; digital rectal exam].

\section{Discussion}

The demographic impact was also identified in this study; $>51 \%$ of the diagnosed cases live in Gaza city. This result is not consistent with previous study done by Abu-El-Noor [17], which showed the highest incidence, was in northern governorate.

This result illustrates the strong link between cigarette smoking and prostate cancer [17] [18]. This is consistent with Arafa's study, which showed that only $10 \%$ of the studied population had a family history of prostate cancer [19]. The recorded symptoms are closely consistent with previous related studies [20]-[22].

The higher the Gleason score, the more aggressive the cancer, and the more likely it is to spread. The percentages, which have been showed, previously are bad news and give an alert to be more serious to find ways to detect the prostate cancer earlier. This result is proved by previous related studies performed by [19] [23] [24]. Regarding prostate specific antigen (PSA) (shown in Figure 4), there were four patients (9.7\%) with normal PSA levels, which mean that normal result does not exclude cancer, PSA test is not accurate for all cases, therefore in our study the specificity of PSA is $90.2 \%$. Regarding to prostate cancer complains, the common side effect was dysuria, which revealed that a great influence of prostate tissue alteration on the urinary system [25]. Moreover, negative influence on the sexual life was reported in more than $45 \%$ of cases. Different factors were indicated and attributed to this impotency, which include hormonal therapy (long-term androgen deprivation) and psychological stress. In spite that most of the literature [26] [27] (reported that prostatectomy and radiation therapy are the two most common modalities used in treating prostate cancer, the case in the Gaza Strip was different. The most common method used to treat prostate cancer among participants in this study was chemotherapy therapy. About $70.7 \%$ of participants used Chemotherapy therapy as a solo method of treatment compared to $22 \%$ who were treated by prostatectomy.

The overuse of chemotherapy to treat prostate cancer could be due to the relatively old age of patients at the time of diagnosis of prostate cancer and the availability of chemotherapy drugs. The majority of patients $(\mathrm{n}=12$, 29.3\%) was diagnosed with prostate cancer at the age of 70 - 74 years. At such age, with limited facilities available in the Gaza Strip, performing the surgery will be risky and, in the absence of radiation therapy option, the use of chemotherapy will be safer.

Limited use of radiation therapy was attributed to the unavailability of this treatment in Gaza Strip. Patients who would need to be treated with radiation therapy were usually referred to receive treatment outside the Gaza Strip (mostly to Egyptian or Israeli hospitals). With the inability to move outside the Gaza Strip due to the siege against Gaza since June 2006, a very few number of patients could travel outside the Gaza Strip to receive such treatment.

\section{Strategies for Preventing Prostate Cancer}

It is highly recommended to eat G-BOMBS (greens, beans, onions, mushrooms, berries and seeds). These food are powerful with anti-cancer effects. Three cup of cruciferous vegetables weekly is enough to reduce prostate cancer by a percent of $41 \%$ [28]. Also onion vegetables, yellow and orange vegetables that contain or- 
gano-sulfur compounds with anti-cancer effects and reduce the incidence of prostate cancer risk [29]-[31]. New studies proved that those who consumed tomato-based foods reduced the risk of prostate cancer by $35 \%$ [32]. In the other hand, try to reduce consumption of animal protein (meat, eggs and dairy) and fried foods, that has been linked to a greater risk of prostate cancer [33]. Several researchers revealed the importance of vitamin D levels, which highly associated with reduction the possibility of several cancers, including prostate cancer [34]-[36]. Furthermore, do not rely on PSA screening as a method of "early detection" to prevent prostate cancer. Finally, try to be active by practice exercise at least 3 hours a week.

\section{Conclusions}

This research was done in the Gaza Strip to evaluate the cases of cancer prostate that discovered during the year 2014.

The cause of prostate cancer is unknown, but the cancer is thought to be related to risk (predisposing) factors for prostate cancer include advancing age.

As we know from the study, the highest prevalence of prostate cancer was among the participants who were between 70 - 74 (12 of 41 participants who represented $29.3 \%$ of the total population) while the lowest prevalence was among those who were between the ages of 50 - 54 (1 participants who represented $2.4 \%$ of the total sample).

Thus, prostate cancer under age 40 is extremely rare, while it is common in men older than 70 years of age. As a matter of fact, some studies have suggested that among men over 70 years of age, $50 \%-80 \%$ of them may have prostate cancer! More than $80 \%$ of prostate cancers are diagnosed in men older than 65 years of age.

As we noticed from the results, the prevalence of prostate cancer was higher among men who lived in Gaza Governorate (twenty tow (51.2\%) of participants).

Therefore, the Gaza governorate has the most patients with prostate cancer.

The most common type of treatment used by participants was chemotherapy therapy $(n=29,70.7 \%)$ followed by hormonal therapy $(n=17,41.5 \%)$ and prostatectomy $(n=9,22 \%)$. The least common methods used for treatment were radiation therapy and combination of hormonal, radiation, and chemotherapy as only five participants (12.2\%) used each type of these treatment options.

In spite of previous studies that cited prostatectomy and radiation therapy are the two most common modalities used in treating prostate cancer; the most common method used to treat prostate cancer among the new recorded participants in this study was chemotherapy therapy.

\section{Roentgen Group}

Ahmed Younis, Saber Jarada, Ibrahim Abu Iyada, Haitham Abu-Tear, Ghassan El-Hennawi, Fadi Rommana, Randa El-Othmani, Abdullah Abu-Helal.

\section{References}

[1] Scanlon, V.C. and Sanders, T. (2012) Essentials of Anatomy and Physiology. 6th Edition, Pearson, London.

[2] Tsukise, A. and Yamada, K. (1984) Complex Carbohydrates in the Secretory Epithelium of the Goat Prostate. The Histochemical Journal, 16, 311-319. http://dx.doi.org/10.1007/bf01003614

[3] Middleton, R.G., Thompson, I.M., Austenfeld, M.S., Cooner, W.H., Correa, R.J., Gibbons, R.P., et al. (1995) Prostate Cancer Clinical Guidelines Panel Summary Report on the Management of Clinically Localized Prostate Cancer. The Journal of Urology, 154, 2144-2148. http://dx.doi.org/10.1016/S0022-5347(01)66718-1

[4] National Cancer Institute (2015) Personal Communication.

[5] Thompson, I.M., Goodman, P.J., Tangen, C.M., Lucia, M.S., Miller, G.J., Ford, L.G., et al. (2003) The Influence of Finasteride on the Development of Prostate Cancer. The New England Journal of Medicine, 349, 215-524. http://dx.doi.org/10.1056/NEJMoa030660

[6] Walsh, P.C., Epstein, L.I. and Lowe, F.C. (1987) Potency Following Radical Prostatectomy with Wide Unilateral Excision of the Neurovascular Bundle. The Journal of Urology, 138, 823-827.

[7] Talcott, J.A., Rieker, P., Clark, J.A., et al. (1998) Patient-Reported Symptoms after Primary Therapy for Early Prostate Cancer: Results of a Prospective Cohort Study. Journal of Clinical Oncology, 16, 275-283.

[8] Helgason, A.R., Arver, S., Adolfsson, J., Dickman, P., Granath, F. and Steineck, G. (1998) “Potency”: The Validation of Information from a Self-Administered Questionnaire Using Objective Measurements of Night-Time Erections and 
Test-Retest Reliability. The Journal of Urology, November, 1946-1947. http://dx.doi.org/10.1097/00005392-199811000-00117

[9] Perez, M.A., Meyerowitz, B.E., Lieskovsky, G., Skinner, D.G., Reynolds, B. and Skinner, E.C. (1997) Quality of Life and Sexuality Following Radical Prostatectomy in Patients with Prostate Cancer Who Use or Do Not Use Erectile Aids. Urology, 50, 740-746. http://dx.doi.org/10.1016/S0090-4295(97)00327-0

[10] Smith, D., et al. (2000) Quality-of-Life Outcomes for Men with Prostate Carcinoma Detected by Screening. Cancer, 88, 1454-1463. http://dx.doi.org/10.1002/(SICI)1097-0142(20000315)88:6<1454::AID-CNCR25>3.0.CO;2-S

[11] Stanford, J., et al. (2000) Urinary and Sexual Function after Radical Prostatectomy for Clinically Localized Prostate Cancer. JAMA, 283, 354-360. http://dx.doi.org/10.1001/jama.283.3.354

[12] Clark, J.A., Rieker, P., Propert, K.J. and Talcott, J.A. (1999) Changes in Quality of Life Following Treatment for Early Prostate Cancer. Urology, 53, 161-168. http://dx.doi.org/10.1016/S0090-4295(98)00457-9

[13] Palestinian Central Bureau of Statistics (2014) State of Palestine.

[14] Walsh, P.C., DeWeese, T.L. and Eisenberger, M.A. (2007) Clinical Practice. Localized Prostate Cancer. The New England Journal of Medicine, 357, 2696-2705. http://dx.doi.org/10.1056/NEJMcp0706784

[15] Wilt, T.J., MacDonald, R., Rutks, I., Shamliyan, T.A., Taylor, B.C. and Kane, R.L. (2008) Systematic Review: Comparative Effectiveness and Harms of Treatments for Clinically Localized Prostate Cancer. Annals of Internal Medicine, 148, 435-448. http://dx.doi.org/10.7326/0003-4819-148-6-200803180-00209

[16] Wolf, A.M., Wender, R.C., Etzioni, R.B., Thompson, I.M., D’Amico, A.V. and Volk, R.J. (2010) American Cancer Society Guideline for the Early Detection of Prostate Cancer. CA: A Cancer Journal for Clinicians, 60, 70-98. http://dx.doi.org/10.3322/caac.20066

[17] Abu-El-Noor, N. (2011) Barriers to Health Care Utilization Facing Prostate Cancer Survivors Living in Gaza Strip. The Islamic University Journal (Series of Natural Studies and Engineering), 19, 1-21. http://www.iugaza.edu.ps/ar/periodical/

[18] Farkhondeh, P. (2015) Relative Telomere Length Is Associated with Azoospermia in Iranian Men Comparing Healthy Fertile Subjects. 4th International Conference on Urology, Barcelona, 20-22 July 2015. http://urology.conferenceseries.com/abstract/2015/relative-telomere-length

[19] Arafa, M.A., Rabah, D.M., Wahdan, I.H. (2012) Awareness of General Public towards Cancer Prostate and Screening Practice in Arabic Communities: A Comparative Multi-Center Study. Asian Pacific Journal of Cancer Prevention, 13, 4321-4326. http://dx.doi.org/10.7314/APJCP.2012.13.9.4321

[20] Moyer, V.A. (2012) Screening for Prostate Cancer: U.S. Preventive Services Task Force Recommendation Statement. Annals of Internal Medicine, 157, 120-134. http://dx.doi.org/10.7326/0003-4819-157-2-201207170-00459

[21] Sanda, M.G., Dunn, R.L., Michalski, J., Sandler, H.M., Northouse, L., Hembroff, L., et al. (2008) Quality of Life and Satisfaction with Outcome among Prostate-Cancer Survivors. The New England Journal of Medicine, 358, $1250-1261$. http://dx.doi.org/10.1056/NEJMoa074311

[22] Schröder, F.H., Hugosson, J., Roobol, M.J., Tammela, T.L., Ciatto, S., Nelen, V., et al. (2009) Screening and ProstateCancer Mortality in a Randomized European Study. The New England Journal of Medicine, 360, 1320-1328. http://dx.doi.org/10.1056/NEJMoa0810084

[23] Andriole, G.L., Crawford, E.D., Grubb, R.L. Buys, S.S., Chia, D., Church, T.R., et al. (2009) Mortality Results from a Randomized Prostate-Cancer Screening Trial. The New England Journal of Medicine, 360, 1310-1319. http://dx.doi.org/10.1056/NEJMoa0810696

[24] Antonarakis, E.S. and Eisenberger, M.A. (2011) Expanding Treatment Options for Metastatic Prostate Cancer. The New England Journal of Medicine, 364, 2055-2058. http://dx.doi.org/10.1056/NEJMe1102758

[25] Aikawa, K., Yamaguchi, O., Oguro, T., et al. (2012) New Classification for Men with Lower Urinary Tract Symptoms: Cluster Analysis Using the International Prostate Symptom Score. BJU International, 110, 408-412. http://dx.doi.org/10.1111/j.1464-410X.2011.10771.x

[26] Ali, M. (2011) Clinical Presentation, Pathological Pattern and Treatment Options of Prostate Cancer at Al-Azhar University Hospitals Over the Last 30 Years. African Journal of Urology, 17, 135-140.

[27] Johansson, J.-E., Holmberg, L., Johansson, S., Bergstrom, R. and Adami, H.-O. (1997) Fifteen-Year Survival in Prostate Cancer: A Prospective, Population-Based Study in Sweden. JAMA, 277, 467-471. http://dx.doi.org/10.1001/jama.1997.03540300035030

[28] Kirsh, V.A., Peters, U., Mayne, S.T., et al. (2007) Prospective Study of Fruit and Vegetable Intake and Risk of Prostate Cancer. Journal of the National Cancer Institute, 99, 1200-1209. http://dx.doi.org/10.1093/jnci/djm065

[29] Galeone, C., Pelucchi, C., Levi, F., et al. (2006) Onion and Garlic Use and Human Cancer. The American Journal of Clinical Nutrition, 84, 1027-1032. 
[30] Hsing, A.W., Chokkalingam, A.P., Gao, Y.T., et al. (2002) Allium Vegetables and Risk of Prostate Cancer: A Population-Based Study. Journal of the National Cancer Institute, 94, 1648-1651. http://dx.doi.org/10.1093/jnci/94.21.1648

[31] Wolk, A. (2005) Diet, Lifestyle and Risk of Prostate Cancer. Acta Oncologica, 44, 277-281. http://dx.doi.org/10.1080/02841860510029572

[32] Giovannucci, E. (2002) A Review of Epidemiologic Studies of Tomatoes, Lycopene, and Prostate Cancer. Experimental Biology and Medicine (Maywood), 227, 852-859.

[33] Vance, T.M., Su, J., Fontham, E.T., Koo, S.I. and Chun, O.K. (2013) Dietary Antioxidants and Prostate Cancer: A Review. Nutrition and Cancer, 65, 793-801. http://dx.doi.org/10.1080/01635581.2013.806672

[34] Holick, M.F. and Chen, T.C. (2008) Vitamin D Deficiency: A Worldwide Problem with Health Consequences. The American Journal of Clinical Nutrition, 87, 1080S-1086S.

[35] Swami, S., Krishnan, A.V. and Feldman, D. (2011) Vitamin D Metabolism and Action in the Prostate: Implications for Health and Disease. Molecular and Cellular Endocrinology, 347, 61-69. http://dx.doi.org/10.1016/j.mce.2011.05.010

[36] Schwartz, G.G. (2014) Vitamin d in Blood and Risk of Prostate Cancer: Lessons from the Selenium and Vitamin e Cancer Prevention Trial and the Prostate Cancer Prevention Trial. Cancer Epidemiology, Biomarkers \& Prevention, 23, 1447-1449. http://dx.doi.org/10.1158/1055-9965.EPI-14-0520 